\title{
DYNAMIC ECONOMIC GROWTH: A NEW METHOD OF APPROACH
}

\section{CRECIMIENTO ECONÓMICO DINÁMICO: UN NUEVO MÉTODO DE ENFOQUE}

\author{
Daniel Villalobos Céspedes \\ Escuela de Administración, Universidad Nacional, Costa Rica \\ daniel.villalobos.cespedes@una.cr
}

Recibido: 10/02/2020 • Aceptado: 11/11/2020

\begin{abstract}
This paper looks at Harrod's fundamental assumptions and equations in 'An essay in dynamic theory' as the foundation for suggesting a better understanding of his postulates on economic growth. The analysis we present attempts to measure the effects of resource composition on the field of economic growth by determining its elasticity and the coefficient of acceleration. By addressing new critical assumptions, key formulas, and methods of approach, some crucial findings provide a strong theoretical model with which to examine dynamic economic growth. Furthermore, this paper offers a brief review of Solow's and Swan's critiques of Harrod's essay. This analysis could inspire further advances in the study of economic growth at the academic level and even in terms of government macroeconomic policies and business decisions.
\end{abstract}

Keywords: Cobb and Douglas; Keynes; Harrod; Domar; Swan; Solow; Warranted/Natural rates of growth; Effective/ Aggregated demands. 


\section{Resumen}

Esta investigación se basa en los supuestos y ecuaciones fundamentales de Harrod en 'Un ensayo sobre teoría dinámica' como núcleo central para sugerir una mejor comprensión de sus postulados sobre el crecimiento económico. El análisis que presentamos pretende medir los efectos de la composición de los recursos en el crecimiento económico determinando su elasticidad y el coeficiente de aceleración. Al abordar nuevos supuestos críticos, fórmulas clave y métodos de enfoque, hallazgos cruciales proporcionan un modelo teórico sólido para examinar el crecimiento económico dinámico. Además, esta investigación ofrece una breve revisión de las críticas de Solow y Swan a ese escrito de Harrod. Esta investigación podría inspirar mayores avances en el estudio del crecimiento económico al nivel académico e inclusive en términos de política macroeconómica de gobierno y decisiones empresariales.

Palabras clave: Cobb and Douglas; Keynes; Harrod; Domar; Swan; Solow; Tasas de crecimiento requerido/natural: Demanda efectiva/agregada.

\section{Introduction}

To Harrod (1939) a dynamic theory necessarily involves thinking dynamically; it requires a mental revolution. His tentative and preliminary attempt is to "provide a framework of concepts relevant to the study of change" (p. 14). The axiomatic basis of his theory proposes that the level of a community's income is the most important determinant of its supply of saving, that its rate of increase determines its demand for saving, and that both are equal. Harrod's relevant concepts of warranted and natural rates of growth were questioned by Solow (1956) who understood that Harrod's warranted concept is strictly related to full employment of the total labor force at each instant, which is not at all the case. In Harrod dynamic system, warranted means an unstable system, a system that oscillates, a moving equilibrium of advance, for which certain conditions are needed.

In such a system, "the trend of growth may itself generate forces making for oscillation (...) maintaining a trend of increase" (Harrod, 1939, p. 16) at a warranted rate; This author suggested that the value of capital goods (both fixed and circulating) "depends on the state of technology and the nature 
of the goods constituting the increment of output" but "not the whole of the new capital is destined to look after the increment of output of consumers' goods" (Harrod, 1939, p. 17). The author begins his analysis by suggesting that producers are satisfied having produced neither more nor less than the right amount maintaining the same rate of growth. For it, "stock in hand and equipment available will be exactly at the level which they would wish to have them" (Harrod, 1939, p. 22). In this quoted text the word 'available' means 'able to be used', 'disposable'.

By relaxing the 'for the moment statement, it follows that there is no unique warranted rate; it depends upon the phase of the trade cycle and the level of activity and at full employment there exist a warranted rate 'proper' to the economy. Harrod's dynamic theory is an attempt to answer Keynes's (1964, p. 4) following concern: "The question [...] of the volume of the available resources [...] has often been treated descriptively. But the pure theory of what determines the actual employment of the available resources has seldom been examined in great detail". In view of foregoing, the main objective of this article is to provide a better understanding of Harrod's dynamic theory by developing a new method of approach based on thinking in terms of trends of increase to reveal the divergence and/or convergence processes of natural and/or warranted rates of growth.

Harrod (1960) describes a dynamic theory as a set of relations between rates of increase (or decrease) of certain magnitudes, which, in turn, are thought of as laws expressing certain necessary relations. Based on this, we construct new formulas denoting relations between production, capital, labor and saving to achieve a new method of approach. The following two sections present the coefficient of acceleration and the resource composition dynamic to explain the natural and/or warranted trends of production growth. The concept of elasticity or velocity as it is relates to resource composition completes our fundamental theoretical model of economic growth which encompasses total, average and relative capital and labor contribution to production growth as well the role of saving in the capital accumulation process, as we propose in sections four and five.

In his critique of Harrod (1939), Solow (1956, p. 65) argued that "all theory depends on assumptions which are not quite true" and "a 'crucial' assumption is one on which the conclusions do depend sensitively, and it is important that crucial assumptions be reasonably realistic". This allows 
us to analyze and discuss by briefly rethinking Solow (1956) and Swan (1956)'s appraisal of Harrod (1939), which is the aim of section six. Finally, we state the conclusions and implications.

\section{Natural and Warranted Growth Rate}

Harrod (1939) suggested that $Y(t)$ is the existing leve/ of income or output, so that $\dot{Y}=d Y / d t$ expresses its increment and $\lambda=(d Y / d t) / Y(t)$ is the actual rate of growth of $\mathrm{Y}(\mathrm{t})$, therefore:

$$
\text { (1) } \lambda=\dot{Y} / Y(t)
$$

He also defined an average warranted rate of growth $\lambda_{w}$ which produces the right amount $\dot{Y}_{w}$ at every point on the path of output:

$$
\text { (2) } \lambda_{w}=\dot{Y}_{w} / Y(t)_{w}
$$

and $\lambda$ would diverge from $\lambda_{w}$ for random or seasonal causes. In total saving $\mathrm{S}(\mathrm{t})=\mathrm{sY}(\mathrm{t}),(\mathrm{s})$ "may be expected to vary, with the size of income, the phase of the trade cycle, institutional changes, etc." (Harrod, 1939, p. 16). At constant $(s)$, it follows that $S=\mathrm{dS} / \mathrm{dt}$ and $(\mathrm{dS} / \mathrm{dt}) / \mathrm{Y}(\mathrm{t})=s(\mathrm{dY} / \mathrm{dt}) / \mathrm{Y}(\mathrm{t})$ so that the growth of saving is equal to a fraction of the actual growth of income:

$$
\text { (3) } \dot{S}=s \dot{Y}
$$

And for the warranted growth of output:

$$
\text { (4) } \dot{S}_{w}=s \dot{Y}_{w}
$$

By equalizing equations (4) and (3), $\dot{S}=\dot{S}_{w} ; \dot{Y}=\dot{Y}_{w}$.

Let $K(t)$ stands for the value of capital goods (both circulating and fix capital) required for $Y(t)$. Let $c=K(t) / Y(t)$ be the actual average capital cost of production and when (c) remains constant, we can derive that $\mathrm{dK} / \mathrm{dt}=\mathrm{c} \mathrm{dY} / \mathrm{dt} \therefore \mathrm{c}=\dot{\mathrm{K}} / \mathrm{Y}$ this is "the value of the increment of capital stock in the period divided by the increment of total output" (Harrod, 1939, p. 17) and if $\dot{Y}=\dot{K} / c$, per equation (1) $\lambda c=\dot{K} / Y(t)$ and "depending on the 
proposition that actual saving in a period $(\ldots)$ is equal to the addition to the capital stock" (Harrod, 1939, p. 18) means that $K=s Y(t)$, and thus:

$$
\text { (5) } \lambda=s / c
$$

From equation (3) $\dot{Y}=\dot{K} / c$ so $\dot{S}=s / c \dot{K}$ and if $\dot{K}=S(t)$ then $\dot{S}=s / c S(t)$ and letting $\dot{S}=S / S(t)$ be the rate of growth of saving:

$$
\text { (6) } s=s / c
$$

Thereby:

$$
\text { (7) } s=\lambda
$$

K measures the amount of additional capital goods to the expected stock $K(t)$, then $k=K / K(t)$, where $(k)$ is the rate of growth of capital, and thus $\mathrm{k}=s \mathrm{Y}(\mathrm{t}) / \mathrm{K}(\mathrm{t})$ from which:

$$
\text { (8) } k=s / c
$$

Linking this result to equation (5), $k=\lambda$; this revealed after replacing $\mathrm{k}=\dot{\mathrm{K}} / \mathrm{K}(\mathrm{t})$ in $\lambda \mathrm{c}=\dot{\mathrm{K}} / \mathrm{Y}(\mathrm{t})$. So far Harrod's assumptions explain by equations (5), (6) and (8) that in a dynamic and perhaps unstable economic system $\lambda=s=k$ is possible, where labor is assumed exogenous.

In the warranted rate of growth, it is supposed that $\mathrm{K}(\mathrm{t})_{\mathrm{w}}$ and $\mathrm{c}_{\mathrm{w}}=\mathrm{K}(\mathrm{t})_{\mathrm{w}} / \mathrm{Y}(\mathrm{t})_{\mathrm{w}}$ and $\mathrm{C}_{\mathrm{w}}$ remaining constant yields $\mathrm{dK}_{\mathrm{w}} / \mathrm{dt}=\mathrm{c}_{\mathrm{w}} \mathrm{dY} \mathrm{Y}_{\mathrm{w}} / \mathrm{dt} \therefore \mathrm{c}_{\mathrm{w}}=\mathrm{K}_{\mathrm{w}} / \mathrm{Y}_{\mathrm{w}}$ and $\dot{\mathrm{Y}}_{\mathrm{w}}=\dot{\mathrm{K}}_{\mathrm{w}} / \mathrm{C}_{\mathrm{w}}$ per equation (2):

$$
\text { (9) } \hat{K}_{w}=c_{w} \lambda_{w} Y(t)_{w}
$$

And if $\dot{K}_{w}=s Y(t)_{w}$ it follows that:

$$
\text { (10) } \lambda_{\mathrm{w}}=s / c_{\mathrm{w}}
$$

Defining $\dot{Y}_{w}=\dot{K}_{w} / c_{w}$ as per equation (4) $\dot{S}_{w}=s / c_{w} \dot{K}_{w}$ and if $\dot{K}_{w}=S(t)$ then $\dot{S}_{\mathrm{w}}=s / \mathrm{c}_{\mathrm{w}} \mathrm{S}(\mathrm{t})_{\mathrm{w}}$ and let $\dot{\mathrm{S}}_{\mathrm{w}}=\dot{\mathrm{S}}_{\mathrm{w}} / \mathrm{S}(\mathrm{t})_{\mathrm{w}}$ be the warranted rate of growth of saving and to have:

$$
\text { (11) } s_{w}=s / c_{w}
$$


and from equation (5) it follows that:

$$
\text { (12) } \dot{s}_{w}=\lambda_{w}
$$

So warranted relative production growth could vary according to the warranted rate of saving growth. Furthermore $\mathrm{k}_{\mathrm{w}}=\mathrm{K}_{\mathrm{w}} / \mathrm{K}(\mathrm{t})_{\mathrm{w}}$ so that $\mathrm{k}_{\mathrm{w}}=s \mathrm{Y}(\mathrm{t})_{\mathrm{w}} / \mathrm{K}(\mathrm{t})_{\mathrm{w}}$ is "conceived to vary with the current level of income, as distinct from its rate of growth" (Harrod, 1939, p. 27):

$$
\text { (13) } k_{w}=s / c_{w}
$$

Per equations (13) and (10) $\mathrm{k}_{\mathrm{w}}=\lambda_{\mathrm{w}}$ and in a dynamic and perhaps unstable warranted economic system $\lambda_{\mathrm{w}}=\dot{s}_{\mathrm{w}}=\mathrm{k}_{\mathrm{w}}$. Equalizing equations (10) and (5) results in $\lambda_{w}=\lambda ; c=c_{w}$, which is Harrod's fundamental equation, assuming "that all new capital goods are required for the sake of the increment of output of consumer's goods accruing" (Harrod, 1939, p. 17). This assumption requires $\mathrm{Y}(\mathrm{t})=\mathrm{Y}(\mathrm{t})_{\mathrm{w}}$; at $\mathrm{c}=\mathrm{c}_{\mathrm{w}}$ per equation $(9) \mathrm{c} \lambda_{\mathrm{w}}=\mathrm{K}_{\mathrm{w}} / \mathrm{Y}(\mathrm{t})_{\mathrm{w}}$ and if $K_{w}=s Y(t)_{w}$ then $\lambda_{w}=s / c \therefore \lambda_{w}=\lambda$.

\section{The Coefficient of Acceleration}

Harrod's warranted rate of growth is a subsystem at a given state of technology of the natural rate of growth system. Harrod's assumption can be systematized by defining the multiplier coefficient; one component is:

$$
\text { (14) } k=\mathrm{K}(\mathrm{t})_{\mathrm{w}} / \mathrm{K}(\mathrm{t})
$$

By replacing $\mathrm{K}(\mathrm{t})_{\mathrm{w}}=k \mathrm{~K}(\mathrm{t})$ in $\mathrm{c}_{\mathrm{w}}=\mathrm{K}(\mathrm{t})_{\mathrm{w}} / \mathrm{Y}(\mathrm{t})_{\mathrm{w}}$ it results in $\mathrm{c}_{\mathrm{w}}=k \mathrm{~K}(\mathrm{t}) / \mathrm{Y}(\mathrm{t})_{\mathrm{w}}$ and:

$$
\text { (15) } k=\mathrm{c}_{\mathrm{w}} \mathrm{Y}(\mathrm{t})_{\mathrm{w}} / \mathrm{K}(\mathrm{t})
$$

And $\mathrm{dK}_{\mathrm{w}} / \mathrm{dt}=k \mathrm{dK} / \mathrm{dt} \therefore \dot{\mathrm{K}}_{\mathrm{w}}=k \dot{\mathrm{K}}$ and since $\mathrm{K}_{\mathrm{w}}=s \mathrm{Y}(\mathrm{t})_{\mathrm{w}}$ and $\dot{\mathrm{K}}=s \mathrm{Y}(\mathrm{t})$ then:

$$
\text { (16) } k=\mathrm{Y}(\mathrm{t})_{\mathrm{w}} / \mathrm{Y}(\mathrm{t})
$$

a counterpart of equation (14) showing how $k$ influences the rate of economic growth. In the case of saving $\mathrm{S}(\mathrm{t})_{\mathrm{w}}=s \mathrm{Y}(\mathrm{t})_{\mathrm{w}}$ and $\mathrm{Y}(\mathrm{t})_{\mathrm{w}}=k \mathrm{Y}(\mathrm{t})$ so $\mathrm{S}(\mathrm{t})_{\mathrm{w}}=\operatorname{skY}(\mathrm{t})$ and: 


$$
\text { (17) } k=\mathrm{S}(\mathrm{t})_{\mathrm{w}} / \mathrm{S}(\mathrm{t})
$$

This is equivalent to equations (14) and (16).

Natural/warranted rates of growth converge at $\lambda Y(t)=\lambda_{w} Y(t)_{w}$ and per equation (16):

$$
\text { (18) } \lambda=k \lambda_{\mathrm{w}}
$$

By matching equations (5) and (10) we get $\lambda / \lambda_{\mathrm{w}}=\mathrm{c}_{\mathrm{w}} / \mathrm{c}$ and let $k=\mathrm{c}_{\mathrm{w}} / \mathrm{c}$ stand for the counterpart of equation (14). Moreover, $K_{w}=s Y(t)_{w}$ it is equivalent to $k \mathrm{~K}(\mathrm{t})=\mathrm{C}_{\mathrm{w}} \mathrm{Y}(\mathrm{t})_{\mathrm{w}}$ so $s=\mathrm{C}_{\mathrm{w}}$, thus warranted saving corresponds to warranted average capital contribution to warranted rate of production growth. In a dynamic economic system in which $\mathrm{K}(\mathrm{t})$ does not vary at a given instant, namely $\underline{\mathrm{K}}(\mathrm{t})$, from equation (14) $k=\mathrm{K}(\mathrm{t})_{\mathrm{w}} / \underline{\mathrm{K}}(\mathrm{t})$ and for sure $(0 \leq k<1)$ and warranted growth rate is below the natural growth rate and it is a warranted 'proper' if full labor force employment is assumed. For this $k \underline{K}(\mathrm{t})=s \mathrm{Y}(\mathrm{t})_{\mathrm{w}}$ and $\mathrm{Y}(\mathrm{t})_{\mathrm{w}}$ tending to $\mathrm{Y}(\mathrm{t})$ (e.g. for random or seasonal causes, the phase of the trade cycle, institutional changes) and $\mathrm{K}(\mathrm{t})_{\mathrm{w}}$ is approaching $\mathrm{K}(\mathrm{t})$ and thus $\mathrm{C}_{\mathrm{W}}=k \underline{K}(\mathrm{t}) / \mathrm{Y}(\mathrm{t})_{w}$; replacing in this expression $k \underline{K}(\mathrm{t})=s \mathrm{Y}(\mathrm{t})_{\mathrm{W}}$ results in $\mathrm{c}_{\mathrm{w}}=s$ and $\dot{S}_{\mathrm{w}}=s \lambda_{\mathrm{w}} \mathrm{Y}(\mathrm{t})_{\mathrm{w}}$.

Additionally, let us state that labor force $L(t)$ is compounded by warranted employed $\measuredangle(t)$ and unemployed $t(t)$ labor force, to set that:

$$
\text { (19) } L(t)=Ł(t), t(t)
$$

If $1=\nvdash(t) / L(t), t(t) / L(t)$ the rate of warranted labor force is $\varepsilon=\nvdash(t) / L(t) ;\{\forall:(0<\varepsilon \leq 1)\}$ at a given instant. Then $\measuredangle(t)=\varepsilon L(t)$ and $\mathrm{d} / \mathrm{dt}=\varepsilon \mathrm{dL} / \mathrm{dt}$ so that $\mathrm{L}=\varepsilon \mathrm{L}$ and $\mathrm{n} \measuredangle(\mathrm{t})=\varepsilon n \mathrm{~L}(\mathrm{t})$, where $(\mathrm{n} ; n)$ represent, in that order, the rates of growth of $\measuredangle(t)$ and $L(t)$. At full employment $(\varepsilon=1 ; \check{n}=n)$ hence $(\varepsilon<1 ; \mathrm{n}<n)$ exposes imbalanced market labor; $Ł(t)<\varepsilon L(t)$. So, $\varepsilon$ is the other component of the coefficient of acceleration.

\section{Resource Composition in Economic Growth}

At $\mathrm{K}(\mathrm{t})_{\mathrm{w}}=k \mathrm{~K}(\mathrm{t})$ and $七(\mathrm{t})=\varepsilon \mathrm{L}(\mathrm{t})$ the warranted resource composition at a given instant is: 
(20) $\hat{r}(\mathrm{t})=k / \varepsilon \mathrm{K}(\mathrm{t}) / \mathrm{L}(\mathrm{t})$

This denotes the line of moving equilibrium required for the inherent tendency of the system to instability, it is delineated by $k / \varepsilon$; the effective coefficient of acceleration of resource composition. By replacing $\mathrm{K}(\mathrm{t})=\mathrm{cY}(\mathrm{t})$ in the previous equation we get:

$$
\text { (21) } \hat{r}(\mathrm{t})=k / \varepsilon \subset Y(\mathrm{t}) / \mathrm{L}(\mathrm{t})
$$

And $k / \varepsilon$ appears to accelerate the average resources productivity; and $Y(t) / L(t)=1 /(1-c)$ thereby the prior equation becomes into $\hat{r}(t)=k / \varepsilon r(t)$.

To better understand the above equation, it is necessary to specify the natural resource composition:

$$
\text { (22) } r(t)=K(t) / L(t)
$$

This equation is contained in equation (20) which simplified is $\hat{\mathrm{r}}(\mathrm{t})=k / \varepsilon \mathrm{r}(\mathrm{t})$ and at $k=\varepsilon ; \hat{\mathrm{r}}(\mathrm{t})=\mathrm{r}(\mathrm{t}) ;$ warranted and natural resource composition would converge. Taking the derivative of equation (21) in terms of (t) so that $\mathrm{d} \hat{r} / \mathrm{dt}=k / \varepsilon \mathrm{c}[(\mathrm{dY} / \mathrm{dt}) / \mathrm{L}(\mathrm{t})-\mathrm{Y}(\mathrm{t}) / \mathrm{L}(\mathrm{t})(\mathrm{dL} / \mathrm{dt}) / \mathrm{L}(\mathrm{t})]$ . Let $n=(\mathrm{dL} / \mathrm{dt}) / \mathrm{L}(\mathrm{t})=\mathrm{L} / \mathrm{L}(\mathrm{t})$ be the rate of growth of labor force and $\dot{Y}=\lambda \mathrm{Y}(\mathrm{t})$ the rate of growth of production to have $\dot{r}_{\mathrm{w}}=k / \varepsilon \mathrm{c}[\dot{\mathrm{Y}} / \mathrm{L}(\mathrm{t})-\mathrm{Y}(\mathrm{t}) / \mathrm{L}(\mathrm{t}) \dot{L} / \mathrm{L}(\mathrm{t})] \therefore \dot{r}_{\mathrm{w}}=k / \varepsilon \mathrm{c}[\lambda \mathrm{Y}(\mathrm{t}) / \mathrm{L}(\mathrm{t})-\mathrm{Y}(\mathrm{t}) / \mathrm{L}(\mathrm{t}) \mathrm{L} / \mathrm{L}(\mathrm{t})] \therefore$

$$
\text { (23) } \dot{r}_{w}=k / \varepsilon[c /(1-c)](\lambda-n)
$$

and $c /(1-c)$ describes the slope of $r(t)$ and at determined instant $r(t)=c /(1-c)$. The fundamental equation of warranted resource composition and production growth rate emerges:

$$
\text { (24) } \dot{r}_{\mathrm{w}}=(\lambda-n) k / \varepsilon \mathrm{r}(\mathrm{t})
$$

It depicts the trend of $\hat{r}(t)$ at changes in $(n, \lambda)$; at $\left(n=\lambda ; r_{w}=0\right)$ it results in Keynes's (1964, p. 55) aggregate demand function, which "relates various hypothetical quantities of employment to the proceeds which their outputs are expected to yield". At $[n>\lambda ; \hat{r}(t)<r(t)]$ increased unemployment of the labor force and potential economic growth is exhibited. If $n=0, \hat{r}(t)$ remains the same and $\lambda>0$ as long as both labor force and capital are available until they run out. It is denoted in this event that $n>0$ represents increments 
in the number of workers required to restore retired workers. These results could be different at changes in $k / \varepsilon$ induced by technological developments, among other circumstances; notable in the case that it makes $k / \varepsilon>1$ and the economy becomes capital intensive. Under these conditions, (c) could diminish and $\dot{r}_{w}$ could decline, but perhaps cushioned by augments in resource productivity $\lambda$.

Differentiating equation (20) with respect to $(t)$ results in $\mathrm{d} \hat{r} / \mathrm{dt}=k / \varepsilon[(\mathrm{dK} / \mathrm{dt}) / \mathrm{L}(\mathrm{t})-\mathrm{K}(\mathrm{t}) / \mathrm{L}(\mathrm{t})(\mathrm{dL} / \mathrm{dt}) \mathrm{L}(\mathrm{t})]$ so $\dot{r}_{\mathrm{w}}=k / \varepsilon[\hat{K} / \mathrm{L}(\mathrm{t})-\mathrm{r}(\mathrm{t}) \dot{L} / \mathrm{L}(\mathrm{t})]$ and given $\hat{K}=s Y(t)$ and $L^{\prime}=n L(t)$ :

$$
\text { (25) } \dot{r}_{\mathrm{w}}=k / \varepsilon[s \mathrm{~s}(\mathrm{t}) / \mathrm{L}(\mathrm{t})-n \mathrm{r}(\mathrm{t})]
$$

Warranted resource composition follows the trajectory of natural resource composition at an acceleration at which capital requires a certain amount of labor and saving to yield a determined level of labor productivity. If increments in labor force cannot be employed at $r(t)$ given $(k / \varepsilon, s)$, it could cause $\hat{r}(t)$ to decline below $\mathrm{r}(\mathrm{t})$, revealing labor force unemployment and potential economic growth. From equation (25) two new outcomes are possible: the first showing that ceteris paribus labor contribution to production defines the slope of $\mathrm{r}(\mathrm{t})$ at each level of production; changes in (c) ceteris paribus will cause oscillations of $\hat{r}(t)$ at $r(t)$ :

$$
\text { (26) } \dot{r}_{\mathrm{w}}=k / \varepsilon[s /(1-\mathrm{c})-\mathrm{nr}(\mathrm{t})]
$$

This shows that if $\dot{r}_{w}=0$ then $r(t)=s / n[1 /(1-c)]$. Given $\dot{\mathrm{K}}=\mathrm{sY}(\mathrm{t}) \therefore \mathrm{kK}(\mathrm{t})=\mathrm{sY}(\mathrm{t}) \therefore s=\mathrm{kc}$ then:

$$
\text { (27) } \dot{r}_{\mathrm{w}}=k / \varepsilon[\mathrm{k} \mathrm{c} /(1-\mathrm{c})-n \mathrm{r}(\mathrm{t})]
$$

At $\dot{r}_{\mathrm{w}}=0 ; \mathrm{r}(\mathrm{t})=\mathrm{k} / n[\mathrm{c} /(1-\mathrm{c})]$ and at $(n=\mathrm{k}) ; \mathrm{r}(\mathrm{t})=\mathrm{c} /(1-\mathrm{c})$ which requires $s=n c=k c$ and thus $\hat{r}_{\mathrm{w}}=k / \varepsilon n[\mathrm{r}(\mathrm{t})-\mathrm{r}(\mathrm{t})]=0$; it explains that ceteris paribus if $n>0$ inevitably $[n=(\mathrm{k}>0)]$ to preserve $\hat{r}(\mathrm{t})=k / \varepsilon \mathrm{r}(\mathrm{t})$.

Equations (26) and (27) are analogous to Solow's fundamental equation in which $\mathrm{k}=s \mathrm{Y}(\mathrm{t}) / \mathrm{K}(\mathrm{t})=s \mathrm{~F}[\mathrm{~K}(\mathrm{t}), \mathrm{L}(\mathrm{t})] / \mathrm{K}(\mathrm{t})=s \mathrm{~F}[1,1 / \mathrm{r}(\mathrm{t})]$ so that $\dot{r}_{\mathrm{w}}=k / \varepsilon[s \mathrm{~F}[\mathrm{~K}(\mathrm{t}), \mathrm{L}(\mathrm{t})] / \mathrm{K}(\mathrm{t}) \mathrm{r}(\mathrm{t})-n \mathrm{r}(\mathrm{t})] \therefore$

$$
\text { (28) } \dot{r}_{\mathrm{w}}=(\mathrm{k}-n) k / \varepsilon \mathrm{r}(\mathrm{t}) \text {. }
$$


Suppose that $(\mathrm{k}=0)$ at actual $k / \varepsilon$ and as per equation (28) $\dot{r}_{\mathrm{w}}=-n k / \varepsilon \mathrm{r}(\mathrm{t})$ and $\dot{r}_{\mathrm{w}}$ will fluctuate at $\mathrm{r}(\mathrm{t})$; due to $\hat{r}(\mathrm{t})=k / \varepsilon \mathrm{r}(\mathrm{t})$ then $\dot{r}_{\mathrm{w}}=-n \hat{\mathrm{r}}(\mathrm{t})$, explaining that actual $\hat{\mathrm{r}}(\mathrm{t})$ might rise (decrease) as $(n)$ varies and it could occur even if $s>0$. On the other hand, if ceteris paribus $(n=0)$ equation (28) becomes $\dot{r}_{\mathrm{w}}=k / \varepsilon \mathrm{k}[\mathrm{c} /(1-\mathrm{c})]=k / \varepsilon \mathrm{kr}(\mathrm{t}) \therefore \dot{r}_{\mathrm{w}}=\mathrm{k} \hat{\mathrm{r}}(\mathrm{t})$ and variations in $(\mathrm{k})$ induce fluctuations of $\dot{r}_{w}$ around $r(t) .{ }^{1}$ The second result requires a definition of the production growth function, which is described in the following section.

Let us introduce the above definition ň $Ł(t)=\varepsilon n L(t)$ after differentiating equation (20), to have:

$$
\text { (29) } \dot{r}_{w}=\left[c_{w} /\left(1-c_{w}\right)\right]\left(\lambda_{w}-n ̃\right)
$$

$c_{w} /\left(1-c_{w}\right)$ is the slope of $\hat{r}(t)$ and $\hat{r}(t)=c_{w} /\left(1-c_{w}\right)$ at a given instant $(t)$, hence:

$$
\text { (30) } \dot{r}_{w}=\left(\lambda_{w}-\check{n}\right) k / \varepsilon r(t)
$$

This is Keynes's (1964, p. 55) effective demand function, which is:

Simply the aggregate income (or proceeds) which the entrepreneurs expect to receive, inclusive of the incomes which they will hand on to the other factors of production, from the amount of current employment which they decide to give (...) the point on the aggregate demand function which becomes effective because, taken in conjunction with the conditions of supply, it corresponds

1 Recall Solow's (1956, p. 70) assumption: "if the capital-labor ratio (...) should ever be established, it will be maintained, and capital and labor will grow thenceforward in proportion. By constant returns to scale, real output will also grow at the same relative rate $n$, and output per head of labor force will be constant". It does not necessarily reflect a natural rate of growth, because for $(r)$ to be stable it is required that $n r=\mathrm{kr} \therefore n \mathrm{r}=s \mathrm{~F}(\mathrm{r}, 1)$; $\mathrm{kr}=s \mathrm{~F}(\mathrm{r}, 1)$. At $n r>[\mathrm{kr}=s \mathrm{~F}(\mathrm{r}, 1)]$ capital investment must increase proportionally to $(s)$ to keep (r) value ever established; to say: $r=(s / k) F(r, 1)$ and of course $r=s F(r, 1) / s F(r, 1)=1$ proves that $\dot{r}=0$ and productive curve $y=F(r, 1)$ also keeps its value but $Y=F(K, L)$ and if $r=K / L$ then $Y=F(r, 1) L$ will be higher than before showing a greater level of production by the amount $\mathrm{d} Y / \mathrm{dt}=\mathrm{F}(\mathrm{r}, 1) \mathrm{dL} / \mathrm{dt} \therefore \dot{\mathrm{Y}}=\mathrm{F}(\mathrm{r}, 1) \mathrm{L}$. Hence, $n \mathrm{r}>[\mathrm{kr}=s \mathrm{~F}(\mathrm{r}, 1)]$ explains a new (lower) position of the natural rate of growth because of $n_{2}>n_{1}$ which indicates a greater potential for economic growth, and the prior location becomes the warranted rate of growth denoting unemployed labor force perhaps due to shortage of capital which inhibits $\dot{r}>0$. Solow (1957) makes an effort to better explain this issue. Additionally: "Even without technological progress, capital accumulation increases labor productivity, at least to a certain point, both because more capital is used per workman in each industry and because there is a shift of labor to industries that use more capital and can afford to pay a higher wage" (Domar E. , 1946, pp. 138-139). 
to the level of employment which maximises the entrepreneur's expectation of profit.

Matching equations (30) and (24), the possibility is shown for these two rates to coincide: $\left(\lambda-\lambda_{\mathrm{w}}\right)=(n-\mathrm{n})$ and if in a specific point of time $(n=\mathrm{n})$ then $\lambda=\lambda_{\mathrm{w}}$ . The rate $(s)$ plays a role in this point of equilibrium: inserting $\dot{K}=s Y(t)$ and n̆Ł $=\varepsilon n L$ into $\dot{r}_{\mathrm{w}}=k / \varepsilon[\dot{K} / \mathrm{L}(\mathrm{t})-\mathrm{r}(\mathrm{t}) \dot{L} / \mathrm{L}(\mathrm{t})]$ and after simplifying the result, $\dot{r}_{\mathrm{w}}=\left[s /(1-\mathrm{c})_{\mathrm{w}}-\mathrm{n} k / \varepsilon \mathrm{r}(\mathrm{t})\right]$ and $\hat{\mathrm{r}}(\mathrm{t})=k / \varepsilon \mathrm{r}(\mathrm{t})$ in order for:

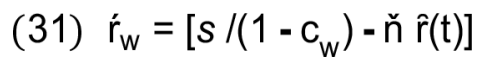

Equalizing this equation with equation (26) and simplifying the result, $\left.k / \varepsilon s /(1-\mathrm{c})-\mathrm{s} /\left(1-\mathrm{c}_{\mathrm{w}}\right)\right]=[n-\check{\mathrm{n}}] \hat{\mathrm{r}}(\mathrm{t})$ and at $(n=\mathrm{n}) ; k / \varepsilon=(1-\mathrm{c}) /\left(1-\mathrm{c}_{\mathrm{w}}\right)$; substituting this expression in equation (26) it is found that $s /(1-\mathrm{c})=n \mathrm{r}(\mathrm{t})]$ and $\dot{r}_{\mathrm{w}}=0$. In addition, $s=n c$, which when replaced in the preceding definition gives $r(t)=c /(1-c)$. Similarly, $s=h_{c} c_{w}$ so that equation (31) gives $\dot{r}_{\mathrm{w}}=\left[\mathrm{n} \mathrm{c}_{\mathrm{w}} /\left(1-\mathrm{c}_{\mathrm{w}}\right)-\mathrm{n} \tilde{\mathrm{r}}(\mathrm{t})\right] \therefore \dot{\mathrm{r}}_{\mathrm{w}}=[\hat{\mathrm{r}}(\mathrm{t})-\hat{\mathrm{r}}(\mathrm{t})] \mathrm{n} \quad \therefore \dot{r}_{\mathrm{w}}=0$. If $(\check{\mathrm{n}}=\mathrm{k}) ; s=\mathrm{kc}_{\mathrm{w}}$ and $\dot{r}_{w}=\left[k c_{w} /\left(1-c_{w}\right)-n ̌ r(t)\right]$, then:

$$
\text { (32) } \dot{r}_{w}=[k-n ̃] r(t)
$$

Once equations (32) and (28) are harmonized, $(\mathrm{k}-\mathrm{n}) \hat{\mathrm{r}}(\mathrm{t})=(\mathrm{k}-n) k / \varepsilon \mathrm{r}(\mathrm{t})$, hence:

$$
\text { (33) } \hat{r}(t)=[(k-n) /(k-\check{n})] k / \varepsilon r(t)
$$

This equation elucidates the fundamental reasons why $\hat{r}(t)$ might fluctuate around $\mathrm{r}(\mathrm{t})$; at $(\breve{\mathrm{n}}=n) ; k / \varepsilon=1$ it is unveiled that $\hat{\mathrm{r}}(\mathrm{t})=\mathrm{r}(\mathrm{t})$; precisely at the point of warranted/natura/ rates of growth stability or at the equilibrium of effectivel aggregated demand functions, when $(n=\check{n}) ;\left(c=c_{w}\right) ; r_{w}=0 ; \lambda=\lambda_{w}$.

\section{Warranted and Natural Production Growth Function}

This theoretical analysis suggests that Harrod's dynamic economic growth basically combines capital goods namely $\mathrm{K}(t)_{\mathrm{w}}$ and labor $\measuredangle(\mathrm{t})$ to provide a warranted level of production. The warranted production function might be:

(34) $Y(t)_{w}=F[k K(t), \varepsilon L(t)]$ 
As per equation (20), the prior equation is transformed into:

$$
\text { (35) } Y(t)_{w}=F[\hat{r}(t), 1] \varepsilon L(t)
$$

It defines the average warranted labor productivity at a given $\hat{r}(t)$; $\mathrm{Y}(\mathrm{t})_{\mathrm{w}} / \varepsilon \mathrm{L}(\mathrm{t})=\mathrm{F}[\hat{\mathrm{r}}(\mathrm{t}), 1]$ is the warranted average labor's productivity curve, and at $\measuredangle(t)=\varepsilon L(t)$ then $Y(t)_{w} / t(t)=F[\hat{r}(t), 1]:^{2}$

$$
\text { (36) } y_{k}=F[\hat{r}(t), 1]
$$

At $\measuredangle(t)=\varepsilon L(t)$ function (35) turns into an effective warranted production function $Y(t)_{w}=F[\hat{r}(t), 1] \measuredangle(t)$ whose derivative provides that $\mathrm{dY}_{\mathrm{w}} / \mathrm{dt}=\mathrm{f}[\hat{\mathrm{r}}(\mathrm{t}), 1] \mathrm{d} / \mathrm{dt} \therefore \dot{Y}_{\mathrm{w}}=\mathrm{f}[\hat{\mathrm{r}}(\mathrm{t}), 1] \mathrm{L}$. which in terms of warranted average rate of labor's productivity is:

$$
\text { (37) } \lambda_{k}=\left(1-c_{w}\right) \text { ňy } y_{t}
$$

ceteris paribus ( $\check{n}>0 ; \lambda_{K}=n$ ) capital's and labor's productivity remains the same.

The derivative of function (32) in terms of $(\mathrm{t})$ gives:

$$
\text { (38) } \dot{\mathrm{Y}}_{\mathrm{w}}=\mathrm{f}(k \dot{\mathrm{K}}, \varepsilon \dot{L})
$$

And if $K=s Y(t)$ at a determined point of production processes, the previous function is $\grave{Y}_{\mathrm{w}}=\mathrm{f}[k s \mathrm{Y}(\mathrm{t}), \varepsilon L \mathrm{~L}]$ and per equation (16) $\mathrm{Y}(\mathrm{t})_{\mathrm{w}}=k \mathrm{Y}(\mathrm{t})$ so that $\dot{Y}_{\mathrm{w}}=\mathrm{f}\left[s \mathrm{~s}(\mathrm{t})_{\mathrm{w}}, \varepsilon n \mathrm{~L}(\mathrm{t})\right]$ and since $\breve{\mathrm{n}} \mathrm{t}(\mathrm{t})=\varepsilon n \mathrm{~L}(\mathrm{t})$ then:

$$
\text { (39) } \dot{Y}_{w}=f\left[s Y(t)_{w}, \grave{n} Ł(t)\right]
$$

It follows that $\lambda_{w} Y(t)_{w}=f\left[s Y(t)_{w}\right.$, n̆Ł $\left.(t)\right]$, so:

$$
\text { (40) } \lambda_{w}=f\left[s,\left(1-c_{w}\right) \text { ň }\right]
$$

At a warranted rate of growth, it is a condition $s=$ ňc ${ }_{w}$ which substituted in the above function, can be useful "when production takes place under the

2 In contrast Solow's productivity curve (1956, pp. 69-71) depicts natural labor productivity according to Harrods' definition (1939, p. 30). 
usual neoclassical conditions of variable proportions and constant returns to scale" (Solow, 1956, p. 73):

$$
\text { (41) } \lambda_{w}=f(\check{n})=f\left(s / c_{w}\right)
$$

Let this be the warranted neoclassical condition, which is also Keynes's effective demand; if $\lambda_{w}=0$ in function (40) then $|-n=s|=\left[1 /\left(1-c_{w}\right)\right]$ and if $s={ }_{n} c_{w}$ then $\hat{r}(t)=\left[c_{w} /\left(1-c_{w}\right)\right]$. After inserting $\check{n}=s / c_{w}$ in function (40) another result is: $\lambda_{w}=f[1,1 / \hat{r}(t)] s$ where:

$$
\text { (42) } y_{K}=F[1,1 / \hat{r}(t)]
$$

If $(\check{\mathrm{n}}=\mathrm{k})=s / \mathrm{c}_{\mathrm{w}}$ then $s=\mathrm{kc}_{\mathrm{w}}$, so that:

$$
\text { (43) } \lambda_{K}=\mathrm{kc}_{\mathrm{w}} y_{\mathrm{K}}
$$

If $y_{\mathrm{K}}=y_{\mathrm{K}} \therefore \mathrm{F}[\hat{\mathrm{r}}(\mathrm{t}), 1]=\mathrm{F}[1,1 / \hat{\mathrm{r}}(\mathrm{t})]$ the result will be $\hat{\mathrm{r}}(\mathrm{t})=1$ and by equalizing equations (43) and (37) $\check{n} / k=c_{w} /\left(1-c_{w}\right)$ where $\mu_{w}=\check{n} / k$ is the elasticity or velocity of $\hat{\mathrm{r}}(\mathrm{t})$, so that:

$$
\text { (44) } \mu_{w}=c_{w} /\left(1-c_{w}\right)
$$

Now it is feasible to measure $\mathrm{C}_{\mathrm{w}}$ at each instant:

$$
\text { (45) } \mathrm{c}_{\mathrm{w}}=\mu_{\mathrm{w}} /\left(1+\mu_{\mathrm{w}}\right)
$$

When production processes are labor intensive it occurs that $\left(0<\mu_{\mathrm{w}}<1\right)$ and capital contribution to production growth could be lesser than that of labor. In a capital-intensive production process $\left(\mu_{w}>1\right)$ and capital contribution will be greater than that of labor.

When $K=k K(t)$ function (38) reveals warranted production growth at both $\mathrm{K}(\mathrm{t})_{\mathrm{w}}$ and $\measuredangle(\mathrm{t})$ levels: $\dot{\mathrm{Y}}_{\mathrm{w}}=\mathrm{f}(k \mathrm{kK}(\mathrm{t}), \varepsilon \dot{L})$. Also $\mathrm{n} \measuredangle(\mathrm{t})=\varepsilon n \mathrm{~L}(\mathrm{t})$ and $\mathrm{K}(\mathrm{t})_{\mathrm{w}}=k \mathrm{~K}(\mathrm{t})$, hence:

(46) $\grave{Y}_{w}=f\left[k K(t)_{w}, \grave{n} Ł(t)\right]$ 
Equalizing this function with function (39) results in $\mathrm{kK}(\mathrm{t})_{\mathrm{w}}=s \mathrm{~s}(\mathrm{t})_{\mathrm{w}}$ which proves that $s=\mathrm{kc}_{\mathrm{w}}$, as suggested before. Function (46) can also be expressed as $\lambda_{w} Y(t)_{w}=f\left[k K(t)_{w}\right.$, ň $\left.(t)\right]$ and $\lambda_{w}=f\left[k K(t)_{w} / Y(t)_{w}\right.$, n̆Ł $\left.(t) / Y(t)_{w}\right]$ so that:

$$
\text { (47) } \lambda_{w}=f\left[k c_{w},\left(1-c_{w}\right) n ̃\right]
$$

This also arises from function (40) after substituting $s=\mathrm{kc}_{\mathrm{w}}$. Multiplying both sides of that function by $Y(t)_{w}$ results in $\lambda_{w} Y(t)_{w}=f\left[k c_{w},\left(1-c_{w}\right) n ̃\right] Y(t)_{w}$

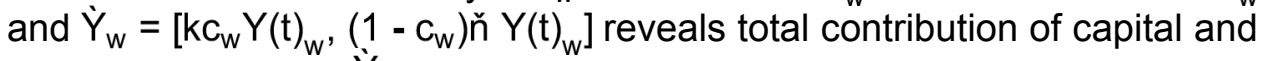
labor to the value of $\dot{Y}_{w}$ For the additional capital it is:

$$
\text { (48) } \dot{\mathrm{Y}}_{\mathrm{K}(\mathrm{t})_{\mathrm{w}}}=\mathrm{kc} \mathrm{c}_{\mathrm{w}} \mathrm{Y}(\mathrm{t})_{\mathrm{w}}
$$

where $\mathrm{kc}_{\mathrm{w}}=\dot{\mathrm{Y}}_{\mathrm{K}(\mathrm{t})_{\mathrm{w}}} / \mathrm{Y}(\mathrm{t})_{\mathrm{w}}$ and let $\lambda_{\mathrm{K}(\mathrm{t})_{\mathrm{w}}}=\grave{\mathrm{Y}}_{\mathrm{K}(\mathrm{t})_{\mathrm{w}}} / \mathrm{Y}(\mathrm{t})_{\mathrm{w}}$ be the average contribution of capital, so that:

$$
\text { (49) } \lambda_{K(t)}=k_{w} c_{w}
$$

And the relative contribution is:

$$
\text { (50) } \quad \lambda_{\mathrm{K}(\mathrm{t})_{\mathrm{w}}} / \mathrm{k}=\mathrm{c}_{\mathrm{w}}
$$

For the added labor total contribution is:

$$
\text { (51) } \grave{Y}_{\mathrm{L}(\mathrm{t})}=\left(1-\mathrm{C}_{\mathrm{w}}\right) \tilde{n} Y(t)_{w}
$$

And $\lambda_{K(t)}=\grave{Y}_{K(t)} / Y(t)_{w}$ is its average contribution, from which:

$$
\text { (52) } \lambda_{t(t)}=\left(1-c_{w}\right) \text { n̆ }
$$

and its relative contribution is:

$$
\text { (53) } \lambda_{\mathrm{t}(\mathrm{t})} / \mathrm{n}=\left(1-\mathrm{c}_{\mathrm{w}}\right)
$$

Per equations (49) and (52) which are equivalents of equations (43) and (37), respectively, function (47) is redefined as:

$$
\text { (54) } \lambda_{w}=f\left[\lambda_{K(t)_{w}}, \lambda_{k(t)}\right]
$$


The warranted rate of growth is influenced by the fundamental conditions of the natural rate of growth. In function (38) $\lambda_{\mathrm{w}} \mathrm{Y}(\mathrm{t})_{\mathrm{w}}=\mathrm{f}[\mathrm{kkK}(\mathrm{t}), \varepsilon n \mathrm{~L}(\mathrm{t})]$ and if $\nvdash(\mathrm{t})=\varepsilon \mathrm{L}(\mathrm{t})$ and $\mathrm{K}(\mathrm{t})_{\mathrm{w}}=k \mathrm{~K}(\mathrm{t})$ then:

$$
\text { (55) } \lambda_{\mathrm{w}} \mathrm{Y}(\mathrm{t})_{\mathrm{w}}=\mathrm{f}\left[\mathrm{kK}(\mathrm{t})_{\mathrm{w}}, n \nvdash(\mathrm{t})\right]
$$

This function makes visible the available capital and labor force effectively employed in a specific period of production. Per this new function $\lambda_{\mathrm{w}}=\mathrm{f}\left[\mathrm{kK}(\mathrm{t})_{\mathrm{w}} / \mathrm{Y}(\mathrm{t})_{\mathrm{w}}, n 七(\mathrm{t}) / \mathrm{Y}(\mathrm{t})_{\mathrm{w}}\right]$ and thus:

$$
\text { (56) } \lambda_{\mathrm{w}}=f\left[k c_{\mathrm{w}},\left(1-\mathrm{c}_{\mathrm{w}}\right) n\right]
$$

This function is useful in depicting dynamic instability in the economic growth system due to the fact that $(\mathrm{k}, n)$ are related to the natural increments of capital and labor force, and for this reason might reveal the unemployment of those available resources at $k / \varepsilon$. Suppose $\lambda_{\mathrm{w}}=0$, so:

$$
\text { (57) }|-n / k| \geq c_{w} /\left(1-c_{w}\right)
$$

In this case $\mu=n / \mathrm{k}$ is the elasticity or velocity of natural resource composition, which should be greater or lesser than or equal to the velocity of warranted resource composition $\mu_{w} ;(\mu=n / k) \geqq\left(\mu_{w}=\check{n} / k\right)$. This will depend on the momentums of the economic growth system, where movements are depicted by the product mass by velocity and $\left(\mu, \mu_{w}\right)$ reflects the oscillating movements in the gravitational field of economic growth $\left(\dot{Y}, \dot{Y}_{w}\right)$ tracked by $(n, \check{n}, \mathrm{k})$ and accelerated by $k / \varepsilon$.

Natural momentum: $\dot{\mathrm{Y}}=[\dot{\mathrm{K}}, \mathrm{L}] \therefore \lambda \mathrm{Y}(\mathrm{t})=[\mathrm{kK}(\mathrm{t}), n \mathrm{~L}(\mathrm{t})]$ where the masses are $\mathrm{Y}(\mathrm{t}), \mathrm{K}(\mathrm{t}), \mathrm{L}(\mathrm{t})$ so that the respective velocities are $\lambda, \mathrm{k}, n$ from which $Y(t)=F[K(t), L(t)]$ in momentum zero and $\lambda Y(t)$ is the variation of $Y(t)$ at $\lambda$ velocity as a result of the velocity $(\mathrm{k})$ by mass $\mathrm{K}(\mathrm{t})$ for capital and velocity $(n)$ by mass $L(t)$ for labor force: $\lambda=f(\mu)$. In this case, some centrifugal forces include ignition of a field in motion toward instability, increase in population, accumulation of capital and savings, science, technological improvement and the work/leisure preference schedule (Harrod R. F., 1939, p. 30). Warranted momentum: $\grave{Y}_{\mathrm{w}}=\mathrm{f}(k \dot{\mathrm{K}}, \varepsilon \dot{\mathrm{L}})=\lambda_{\mathrm{w}} \mathrm{Y}(\mathrm{t})_{\mathrm{w}}=\mathrm{f}[k \mathrm{kK}(\mathrm{t}), \varepsilon n \mathrm{~L}(\mathrm{t})]$ is the product of such masses by such velocities $(\check{n}, k)$ whose outcome is warranted economic growth: $\lambda_{w}=f\left(\mu_{w}\right)$. It is a moving equilibrium caused by the circumstances operating as centripetal and other inertial 
forces, conjugated by $(k / \varepsilon)$; including government policies (e.g. monetary, fiscal, commerce), the trade cycle and level of activity, producer and labor organizations and rules (Harrod R. F., 1939, p. 22).

These two momentums can be exposed by conjunction: $\lambda Y(t)=\lambda_{w} Y(t)_{w} \therefore[k K(t), n L(t)]=[k \mathrm{kK}(\mathrm{t}), \varepsilon n L(t)] \quad$ so that $(1-k) \mathrm{kK}(\mathrm{t})=-(1-\varepsilon) n \mathrm{~L}(\mathrm{t})$ and thus $|-n / \mathrm{k}|=[(1-k) /(1-\varepsilon)] \mathrm{K}(\mathrm{t}) / \mathrm{L}(\mathrm{t})$ hence:

(58) $\mu=(1-k) /(1-\varepsilon) r(t)$

In that system $\mu=\mu_{\mathrm{w}}=\mathrm{r}(\mathrm{t})$ at $(\varepsilon=k)$ ceteris paribus but if $(\varepsilon \neq k)$ the previous equation turns into:

(59) $\mu_{w}=(1-k) /(1-\varepsilon) r(t)$

Which is $\mu_{w}=\hat{r}(t)$ : "The acceleration principle is presented as a leading dynamic determinant" but "there is no inherent tendency for these two [momentums] to coincide" (Harrod R. F., 1939, pp. 26, 30). The role of $\mu=n / \mathrm{k}$ can be clarified by equation (56) by $n=\mu \mathrm{k}$ or $\mathrm{k}=n / \mu$ and:

$$
\text { (60) } \lambda_{\mathrm{w}}=\mathrm{f}\left[\mathrm{c}_{\mathrm{w}},\left(1-\mathrm{c}_{\mathrm{w}}\right) \mu\right] \mathrm{k} ; \lambda_{\mathrm{w}}=\mathrm{f}\left[\mathrm{c}_{\mathrm{w}} / \mu,\left(1-\mathrm{c}_{\mathrm{w}}\right)\right] n
$$

The natural production function can also be defined simply by Solow's production function:

$$
\text { (61) } Y(t)=F[K(t), L(t)]
$$

whose derivative is $\dot{Y}=(\dot{K}, \dot{L})$ so $\lambda=f[k K(t) / Y(t), n L(t) / Y(t)]$ and the natural rate of growth is:

$$
\text { (62) } \lambda=f[c k,(1-c) n]
$$

And if $(n=k) ; \dot{r}=0$ we get the equivalent of function (41) which is also Keynes's aggregated demand:

$$
\text { (63) } \lambda=f(n)=f(\dot{r}-k) ; \lambda=f(k)=f(\dot{r}-n)
$$

At $\dot{r}=0$ and $(\mathrm{k} ; n)>0$ it implies a diminishing contribution. At $\lambda=0$ in equation (62): 
(64) $|-n / k|=c /(1-c)$

This exposes the reasons why equation (57) is expressed as inequality. Also:

$$
\begin{aligned}
& \text { (65) } \mu=c /(1-c) \\
& \text { (66) } c=\mu /(1+\mu)
\end{aligned}
$$

Let $\quad c=F(\mu) \quad$ to obtain 1$): \quad \lim _{\mu \rightarrow 0} F(\mu)=\lim _{\mu \rightarrow 0}\left(\frac{\mu}{1+\mu}\right) \approx 0$ and 2) $\lim _{\mu \rightarrow \infty} F(\mu)=\lim _{\mu \rightarrow \infty}\left(\frac{\mu}{1+\mu}\right) \approx 1$ to conclude that $\{c:(0,1)\}$ thereby (c) descends horizontal asymptote as $\mu>0$.

\section{Saving and Capital Accumulation}

Inserting $\mu_{w}=\check{n} / k \therefore \check{n}=k \mu_{w}$ into function (47) results in $\lambda_{\mathrm{w}}=\mathrm{f}\left[\mathrm{c}_{\mathrm{w}},\left(1-\mathrm{c}_{\mathrm{w}}\right) \mu_{\mathrm{w}}\right] \mathrm{k}$ where $\lambda_{\mathrm{w}}=\mathrm{f}\left[\mathrm{c}_{\mathrm{w}},\left(1-\mathrm{c}_{\mathrm{w}}\right) \mu_{\mathrm{w}}\right] \mathrm{s} / \mathrm{c}_{\mathrm{w}}$ and thus $\lambda_{\mathrm{w}}=2 \mathrm{~s}$ at constant returns to scale. But we can compute the rate of saving by equation (47) after differentiating equation (20) to obtain $\ddot{r}=k-\check{n}$ so that $\lambda_{w}=f\left[(\ddot{r}+\check{n}) c_{w},\left(1-c_{w}\right) \check{n}\right]$ from which $\lambda_{w}=f\left[(\ddot{r}+\check{n}) c_{w},\left(1-c_{w}\right) \bar{n}\right]$ and by $\mathrm{k}=\check{\mathrm{n}} / \mu_{\mathrm{w}}$ will result $\ddot{\mathrm{r}}=\mathrm{n} / \mu_{\mathrm{w}}-\check{\mathrm{n}} \therefore \ddot{\mathrm{r}}=\left[\left(1-\mu_{\mathrm{w}}\right) / \mu_{\mathrm{w}}\right] \mathrm{n}$ in order to

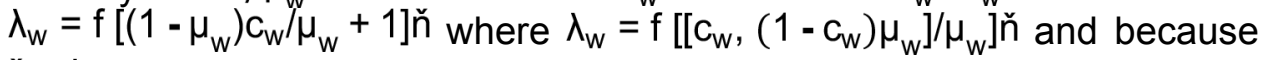
$\mathrm{n}=\mathrm{k} \mu_{\mathrm{w}}$

$$
\text { (67) } \lambda_{w}=f\left[c_{w},\left(1-c_{w}\right) \mu_{w}\right] k
$$

And defining $\mathrm{K}(\mathrm{t})_{\mathrm{w}}=s \mathrm{Y}(\mathrm{t})_{\mathrm{w}}$ so that:

$$
\text { (68) } \mathrm{k}=s \pi / \mathrm{c}_{\mathrm{w}}
$$

be the effective or recorded capital growth rate where $\lambda$ symbolizes the recorded production growth rate. This function turns into:

$$
\text { (69) } \lambda_{w}=f\left[c_{w},\left(1-c_{w}\right) \mu_{w}\right] s \lambda / c_{w}
$$

Here $(s)$ can be disclosed as follows:

$$
\text { (70) } s=\left[\mathrm{c}_{\mathrm{w}} /\left[\mathrm{C}_{\mathrm{w}},\left(1-\mathrm{C}_{\mathrm{w}}\right) \mu_{\mathrm{w}}\right] \lambda_{\mathrm{w}} / \lambda\right.
$$


(s) is the warranted rate of saving to get $\lambda_{w}$ at each instant, which must be compared with the effective $\lambda$; this outcome is also obtained per equation (68). Multiplying both sides of this equation by the recorded $\mathrm{Y}(\mathrm{t})$ the result is the level of saving $S(t)$ at each instant. From this results must be possible to derive the capital depreciation and the replacement and new capital into capital accumulation process (Villalobos C. D., 2020). If $\lambda<\lambda_{w}$ the economy makes inefficient use of saving resulting in an excess of capital accumulation and low depreciation.

\section{Steady Natural Rate of Growth}

"A steady rate of increase implies that a constant fraction of income is saved. If the fraction of income saved is increasing or decreasing, that implies an accelerating or decelerating increase of income" (Harrod R. F., 1960). By inserting Harrod's (1939) definition $\mathrm{K}^{\prime}=s \mathrm{~s}(\mathrm{t})$, from which $\mathrm{k}=s \mathrm{Y}(\mathrm{t}) / \mathrm{K}(\mathrm{t})$, into equation (62) we get Swan's (1956) basic formula $y=(\alpha s Y / K, \beta n)$, which illustrates "the connection between capital accumulation and the growth of the productive labor force" (Swan T. W., 1956, p. 334) measured by resources' share (income) on production growth at constant returns to scale following Cobb and Douglas's (1928) production function, instead of resources' contribution to production growth; from function (62) $\lambda=\mathrm{f}[\mathrm{scY}(\mathrm{t}) / \mathrm{K}(\mathrm{t}),(1-\mathrm{c}) n]$ after substituting the above definition we obtain the natural economic growth rate:

$$
\text { (71) } \lambda=f[s,(1-c) n]
$$

Inserting $s=n c$ into the above function we get $\lambda=f(n)$ and if $n=k$ then $\lambda=\mathrm{f}(\mathrm{k})$. Also, this function provides a key result after inserting $n=\mathrm{s} / \mathrm{c}$ :

$$
\text { (72) } \lambda=s f[1,1 / r(t)]
$$

This explains that increments in production per unit of capital to labor are determined by the appropriate level of saving. This previous function is a key component in both Solow's (1956) fundamental equation and Swan's (1956, p. 335) "basic formula for the rate of growth of output". However, Swan's basic formula provides an essential relationship between resources' share on production growth $(\alpha)$, "when production takes place under the usual neoclassical conditions of variable proportions and constant returns to scale" (Solow, 1956, p. 73) and resources' contribution to production 
growth (c); $y=(\alpha s Y / K, \beta n)$ and $c=K / Y$ so $y=(\alpha s / c, \beta n)$ and by adding $n=s / c$ Swan's basic formula becomes ${ }^{3}$ :

$$
\text { (73) } y=(\alpha, \beta) s / c
$$

Swan's basic formula can be expressed as $y=(\alpha k, \beta n)$ which is the counterpart of function (62) ${ }^{4}$; provided that $\alpha \mathrm{k}=\mathrm{kc} \therefore \alpha=\mathrm{c}$, function (43) is $\lambda=\mathrm{f}[\alpha \mathrm{k},(1-\alpha) n]$ and at $\mathrm{k}=n=\mathrm{s} / \mathrm{c}$ results in $\lambda=\mathrm{f}[\alpha,(1-\alpha)] \mathrm{s} / \mathrm{c}$ :

$$
\text { (74) } \lambda=f(s / c)
$$

It also explains that rate $(s)$ is required for steady $\lambda ; s=f(c \lambda)$ which can be obtained from equation 62 or 63 . From function (56) the corresponding warranted rate of economic growth is $\lambda_{\mathrm{w}}=\mathrm{f}\left[\mathrm{c}_{\mathrm{w}} s \mathrm{Y}(\mathrm{t}) / \mathrm{K}(\mathrm{t}),\left(1-\mathrm{c}_{\mathrm{w}}\right) n\right]$ so that:

$$
\text { (75) } \lambda_{\mathrm{w}}=\mathrm{f}\left[\mathrm{c}_{\mathrm{w}} \mathrm{s} / \mathrm{c},\left(1-\mathrm{c}_{\mathrm{w}}\right) n\right]
$$

Or also:

$$
\text { (76) } \lambda_{w}=f\left[\alpha_{w},\left(1-a_{w}\right)\right] s / c ; \lambda_{w}=f(s / c)
$$

And for Swan's basic formula: $y=\left(\alpha_{w}, \beta_{w}\right) s / c$.

Equation (28) can, therefore, be renewed as follows:

$$
\text { (77) } \dot{r}_{w}=k / \varepsilon[c /(1-c)-r(t)] s / c
$$

This reveals the tendency of warranted resource composition as ceteris paribus the rate of saving varies, denoting an unbalanced production growth. Per equation (24), that condition of economic growth instability can be expressed as $\hat{r}_{\mathrm{w}}=(\lambda-n) \hat{r}(\mathrm{t})$ and at $n=$ s/c will result in:

3 In Swan's (1956) basic formula, any point ( $s$ Y/K) represents Harrod's warranted rate of growth and any point in $(y)$ corresponds to Harrod's natural rate of growth: so, at an equilibrium point $y=s \mathrm{Y} / \mathrm{K}=\mathrm{s} / \mathrm{c}$.

4 Per Cobb and Douglas's (1928) production function, on which Swan's (1956) unclassical case is based, it can be proven that $r s=\alpha k=r c k: Y=F\left[K^{\alpha} L^{1-\alpha}\right.$ and by partial derivative in terms of $\mathrm{K}$ so that $\partial \mathrm{Y} / \partial \mathrm{K}=\mathrm{f}\left[\alpha \mathrm{K}^{\alpha-1} \mathrm{~L}^{1-\alpha}\right]$ and let $r=\partial \mathrm{Y} / \partial \mathrm{K}$ be the rate of profit or capital return to yield $r=\alpha \mathrm{f}(\mathrm{Y} / \mathrm{K}) \therefore r=\alpha / \mathrm{c}$ and thus $\alpha=r \mathrm{c}$; by replacing this result in function (73), we get $y=(r s, \beta n)$, as per Swan's (1956, p. 335) footnote No. 5. 
(78) $\dot{r}_{w}=(\lambda-s / c) k / \varepsilon r(t)$

It is clear that the natural rate of growth is determined by velocities, the rate of saving and the average capital's contribution. Harrod's instability of economic growth motivates Solow's (1956) 'A model of long-run growth' providing the fundamental equation $\dot{r}=s \mathrm{~F}[\mathrm{r}(\mathrm{t}), 1)]-n \mathrm{r}(\mathrm{t})$, which describes the potential trajectory of $r(t)$. Solow's equation comes from the derivative of natural resource composition according to equation (23): $\quad d r / d t=[(d K / d t) / L(t)-K(t) / L(t)(d L / d t) / L(t) \therefore \dot{r}=[\dot{K} / L(t)-K(t) / L(t) L / L(t)]$ and $\dot{r}=[\mathrm{k} \mathrm{K}(\mathrm{t}) / \mathrm{L}(\mathrm{t})-n \mathrm{~K}(\mathrm{t}) / \mathrm{L}(\mathrm{t})]$ so that $\dot{r}=\mathrm{kr}(\mathrm{t})-n \mathrm{r}(\mathrm{t})$ and after replacing $\mathrm{k}=s \mathrm{Y}(\mathrm{t}) / \mathrm{K}(\mathrm{t})$ results in $\dot{r}=s / c \mathrm{r}(\mathrm{t})-n \mathrm{r}(\mathrm{t})$ and if $n=s / \mathrm{c}$ :

$$
\text { (79) } \dot{r}=[r(t)-r(t)] s / c
$$

This equation is tautological, reason for which it reveals only a steady natural rate of growth in Solow's fundamental equation. By partially reverting Solow's equation it will yield $Y(t) / K(t)=F[[K(t), L(t)] / K(t)]=F[r(t), 1)]=1 / c$ and we can rewrite it as follows:

$$
\text { (80) } \dot{r}=s / c-n r(t)
$$

which can be achieved for labor by following the previous process: $\dot{r}=[\dot{K} / L(t)-n r(t)]$ and then substituting $K^{\prime}=s Y(t)$ to get the counterpart of equation (26):

$$
\text { (81) } \dot{r}=[s[1 /(1-c)]-n r(t)]
$$

And $s=n c:$

$$
\text { (82) } \dot{r}=[n[\mathrm{c} /(1-\mathrm{c})]-n \mathrm{r}(\mathrm{t})]
$$

And $\mu=c /(1-c)$ is a result of the derivative of Solow's production function $\mathrm{Y}(\mathrm{t})=\mathrm{F}[\mathrm{K}(\mathrm{t}), \mathrm{L}(\mathrm{t})]$ to achieve function $(62)$ and $\mathrm{at} \lambda=0$ :

$$
\text { (83) } \dot{r}=[\mu-r(t)] s / c
$$

At $\lceil\mu=1 ; \dot{r}=0 ; \lambda=f(\dot{r})=0]$ and if $k=\varepsilon ; \mu=\hat{r}(t)$. 


\section{Conclusions}

As the introduction claims, the purpose of this study is to provide a better understanding of Harrod's dynamic theory and to offer a new method of approach to attack some gaps. By working on the fundamental assumptions and suggestions supporting Harrod's basic concepts and equations, we devised a new set of relations that provides an analytical model for dynamic economic growth. An interesting contribution of this study is having found new formulas with which to measure the coefficient of acceleration, resource composition, the rate of thrift for the require capital accumulation at each instant and their influence in the instability of warranted and natural production function. We also derived velocity as the elasticity of resource composition with which precise capital and labor contribution to production growth (Villalobos C. D., 2019; 2019a; 2020).

We conclude that warranted and natural rates of growth belong to the same system but they do not necessarily converge due to the fact that full employment of resources might be difficult to achieve. When convergence between these rates of growth occurs it appears as a moving equilibrium depending on the velocities of warranted and natural rates of growth in capital and labor, the state of the art or technique acting as the accelerator of warranted resource composition, and the capital and saving accumulation, among other centrifugal and centripetal social forces.

In such a system, Solow's (1956, p. 73) basic conclusion could occur as a moving equilibrium where momentarily the system can adjust at the rate of growth of the labor force but not approach a state of steady proportional expansion. Cobb and Douglas (1928) questioned whether the increase in production is purely fortuitous or is primarily caused by technique, and the degree to which it responds to changes in the quantity of labor or capital. This strongly asserts Harrods' natural and warranted rates of growth divergence, because natural rates of growth could be influenced by random events, but the warranted rate could assure that the processes of distribution are modeled at all closely upon those of the production of value, as suggested by Cobb and Douglas (1928). It cannot occur only 'by a fluke' (Swan T. W., 1956, p. 343), not as an odd piece of luck but as a consequence of demand-supply adjustments (Solow, 1956, p. 77). 
We believe that these results could contribute to improving economic scientific knowledge on economic growth and be useful in enhancing government macroeconomic policies for a better allocation of available economic resources. This, in turn, will help to maintain a dynamic yet stable warranted rate of economic growth, thereby making business decisions less risky. New research in this field must pay explicit attention to variables such as the rate of interest, capital and labor costs and product pricing to achieve advances based on in this new model.

\section{References}

Cobb, W. C., \& Douglas, H. P. (1928). A theory of production. The American Economic Review, 18(1), 139-165.

Domar, E. D. (1946). Capital Expansion, Rate of Growth, and Employment. Econometrica, 14(02), 137-147.

Harrod, R. F. (1939). An essay in dynamic theory. The Economic Journal, 49(193), 14-33. doi: https://doi.org/10.2307/2225181.

Harrod, R. F. (1960). Second essay in dynamic theory. The Economic Journal, 70(178), 277-293. doi: https://doi.org/10.2307/2228728.

Keynes, J. M. (1964). The general theory of employment, interest, and money (First ed.). United States of America: A Harvest/HBJ Book.

Solow, M. R. (1956). A contribution to the theory of economic growth. The Quarterly Journal of Economics, 70(1), 65-94. doi: https://doi. org/10.2307/1884513.

Solow, M. R. (1957). Technical change and the aggregate production function. The Review of Economics and Statistics, 39(3), 312-320. doi: https://doi.org/10.2307/1926047.

Swan, T. W. (1956). Economic growth and capital accumulation. Economic Record(32), 334-361. Doi: https://doi.org/10.1111/j.1475-4932.1956. tb00434.x. 
Villalobos, C. D. (2019). Crecimiento económico: Convergencia y divergencia. Economía y Sociedad, 24(55), 1-30. doi: http://dx.doi. org/10.15359/eys.23-55.3.

Villalobos, C. D. (2019a). Crecimiento económico: Contribución y participación de los recursos. ABRA, 40(59). doi: https://doi. org/10.15359/abra.39-59.1

Villalobos, C. D. (2020). Economic growth: Productivity, thrift and capital accumulation. Economía y Sociiedad, 25(57). 
